Article

\title{
Evaluation and Calibration of MODIS Near-Infrared Precipitable Water Vapor over China Using GNSS Observations and ERA-5 Reanalysis Dataset
}

\author{
Dantong Zhu ${ }^{1,2}$, Kefei Zhang ${ }^{1,2,3, *}$, Liu Yang ${ }^{1,2}$, Suqin $\mathrm{Wu}^{1,2}$ and Longjiang $\mathrm{Li}^{1,2}$ \\ 1 Jiangsu Key Laboratory of Resources and Environmental Information Engineering, China University of \\ Mining and Technology, Xuzhou 221116, China; zdt@cumt.edu.cn (D.Z.); tb18160011b2@cumt.edu.cn (L.Y.); \\ suqin_wu@cumt.edu.cn (S.W.); lilongjiang@cumt.edu.cn (L.L.) \\ 2 School of Environment Science and Spatial Informatics, China University of Mining and Technology, \\ Xuzhou 221116, China \\ 3 Satellite Positioning for Atmosphere, Climate and Environment (SPACE) Research Centre, RMIT University, \\ Melbourne, VIC 3001, Australia \\ * Correspondence: profkzhang@cumt.edu.cn
}

Citation: Zhu, D.; Zhang, K.; Yang, L.; Wu, S.; Li, L. Evaluation and

Calibration of MODIS Near-Infrared Precipitable Water Vapor over China Using GNSS Observations and ERA-5 Reanalysis Dataset. Remote Sens. 2021, 13, 2761. https://doi.org/ $10.3390 /$ rs13142761

Academic Editor: Silas Michaelides

Received: 11 June 2021

Accepted: 12 July 2021

Published: 14 July 2021

Publisher's Note: MDPI stays neutral with regard to jurisdictional claims in published maps and institutional affiliations.

Copyright: (c) 2021 by the authors. Licensee MDPI, Basel, Switzerland. This article is an open access article distributed under the terms and conditions of the Creative Commons Attribution (CC BY) license (https:/ / creativecommons.org/licenses/by/ $4.0 /)$.

\begin{abstract}
Water vapor is one of the most important parameters in climatic studies. MODerateresolution Imaging Spectroradiometer (MODIS) is a key instrument and can provide spatially continuous precipitable water vapor (PWV) products. This study was focused on the performance evaluation of the MODIS near-infrared PWV product (MOD-NIR-PWV) over China. For a comprehensive assessment of the performance of MOD-NIR-PWV, PWV retrieved from the measurements at the global navigation satellite systems (GNSS) stations (i.e., GNSS-PWV) and the ERA5 reanalysis dataset (ERA-PWV) from 2013 to 2018 were used as the reference. To investigate the suitability of using ERA-PWV as the reference for the evaluation, ERA-PWV was compared to the high-accuracy GNSS-PWV at 246 GNSS stations and PWV retrieved from radiosonde observations (RS-PWV) at 78 radiosonde stations over China. The results showed that the mean bias and mean root-meansquare (RMS) of the differences between ERA-PWV and GNSS-PWV across all the stations were 0.5 and $1.7 \mathrm{~mm}$, respectively, and the mean correlation coefficient of the two datasets was above 0.96 . The values were 0.4 and $1.9 \mathrm{~mm}$ and 0.97 , respectively, for the differences between ERA-PWV and RS-PWV. This suggests the suitability of ERA-PWV as the reference for the evaluation of MODNIR-PWV. In addition, MOD-NIR-PWV was compared with both GNSS-PWV and ERA-PWV, and their mean bias and mean RMS were 2.9 and $3.8 \mathrm{~mm}$ (compared to GNSS-PWV) and 2.1 and $3.0 \mathrm{~mm}$ (compared to ERA-PWV), respectively. The positive bias values and the non-normal distribution of the differences between MOD-NIR-PWV and both reference datasets imply that a considerable systematic overestimation of MOD-NIR-PWV over China may exist. To mitigate the systematic bias, ERA-PWV was utilized as the sample data due to its spatial continuities, and a grid-based calibration model was developed based on the annual and semiannual periodicities in the differences between MOD-NIR-PWV and ERA-PWV at each grid point. After applying the calibration model to correct MOD-NIR-PWV, the calibrated MOD-NIR-PWV was compared with ERA-PWV and GNSS-PWV for precision and accuracy analysis, respectively. The comparison showed that the model could significantly improve the precision by $94 \%$ and accuracy by $53 \%$, which manifested the effectiveness of the calibration model in improving the performance of MOD-NIR-PWV over China.
\end{abstract}

Keywords: MODIS near-infrared precipitable water vapor; GNSS-PWV; ERA-PWV; grid-based calibration model

\section{Introduction}

Atmospheric water vapor plays a key role in the Earth's radiative balance, hydrological process, energy circulation throughout surface evaporation, transportation, condensation, 
and precipitation processes [1-4]. As one of the most important greenhouse gases, atmospheric water vapor also greatly affects climate change, which involves a positive feedback to global warming and leads to further climate change [5-7]. Therefore, effective quantification of the atmospheric water vapor content is an important task and also a challenge due to the dynamic nature of water vapor in both spatial and temporal domains. Precipitable water vapor (PWV), defined as the total atmospheric water vapor contained in a vertical column from the ground to the specified tropospheric height, is widely used to quantify the atmospheric water vapor content [8-10].

PWV is usually retrieved from observations and Numerical Weather Prediction (NWP) models. The observations are from radiosonde [11], Global Navigation Satellite Systems (GNSS) [3], remote sensing satellites [12], sunphotometer [13], ground-based telescope [14], etc. The NWP models include the Second Modern Era Retrospective analysis for Research and Applications (MERRA-2) [15], fifth-generation European center for medium-range weather forecasts (ECMWF) reanalysis (ERA-5) [16], etc.

Radiosonde is an important traditional method used in the monitoring of PWV variation due to the availability of long-term historic data $[3,11,17,18]$. Various types of atmospheric data can be acquired from radiosonde, e.g., temperature, pressure, and humidity at various altitudes over the radiosonde station of interest. Radiosonde-derived PWV (RS-PWV) can reach $1 \mathrm{~mm}$ accuracy in average weather conditions [19,20]; thus RS-PWV is often used as reference data in the validation of PWV derived from other technologies [21-23]. However, the low temporal resolution (twice per day) of RS-PWV due to the high cost of the one-off balloons [24] limits its applications in some climatic research.

GNSS is a relatively new technique that can be used to obtain PWV time series at high temporal and spatial resolutions, predominantly due to its distinguished characteristics of high accuracy, high sampling frequency, all-weather operability, and global deployment of ground-based GNSS stations [25,26]. Since GNSS-meteorology was first proposed in 1992 by Bevis [10], GNSS-derived PWV (GNSS-PWV) has been studied by several researchers, and the accuracy of GNSS-PWV can reach $2 \mathrm{~mm}$ or even better [27-29]. Nowadays, GNSSPWV is being used for many climatic studies, e.g., weather forecast [30], ENSO [31-33], and drought monitoring [34].

RS-PWV and GNSS-PWV over a ground-based station, as single-point observations, can be used to determine the PWV variations around the area of the station. If a network of ground-based stations is sparsely deployed, the determination of small-scale variations of the PWV can be difficult in the spatial domain. In recent years, with the rapid deployment of more and more remote-sensing sensors aboard satellites, various types of PWV with global coverage are available [5,35-39]. Among these sensors, MODerate-resolution Imaging Spectroradiometer (MODIS) on the NASA Terra and Aqua satellites is one of the most widely used data source since it can provide PWV from the ground surface to the upper troposphere over the globe $[35,37,40]$. MODIS PWV products predominantly provide two types of PWV data derived through the infrared algorithm (MOD-IR-PWV) and near-infrared algorithm (MOD-NIR-PWV), respectively.

Reanalysis datasets from NWP models are another source of PWV [41-45]. They are generated by assimilating atmospheric data from various sources of observations, including synoptic stations, radiosonde stations, satellite sensors, and microwave radiometers [16]. PWV derived from reanalysis datasets, such as ERA5 (ERA-PWV), have good spatialtemporal resolution and continuity, and accuracy of $1.5-3 \mathrm{~mm}$ is reported when RS-PWV and GNSS-PWV are used as the references [46,47].

Previous performance evaluations of the MODIS PWV products over several typical regions in China showed that MODIS PWV presented a typical error in the range from 5 to $12 \mathrm{~mm}$, referring to the GNSS PWV products from the International GNSS Service (IGS), radiosonde data from the Integrated Global Radiosonde Archive (IGRA), and sunphotometer observations from the Aerosol Robotic Network (AERONET) [39,48-53]. Gui et al. [49] conducted a comparison among four PWV products, i.e., MOD-NIR-PWV, RS-PWV, GNSSPWV, and sunphotometer-derived PWV, over China during the period from 2011 to 2013. 
Liu Z. et al. [13] assessed the accuracy of MOD-IR-PWV and MOD-NIR-PWV over a period of several years in the Hong Kong region. Liu H. et al. [54] compared MOD-IR-PWV and MOD-NIR-PWV over China against RS-PWV over 83 radiosonde stations from the IGRA in 2012. Additionally, several comparisons for the performance assessment of MODIS PWV products in the Tibetan Plateau were also conducted $[39,51,55,56]$. However, since the reference data used in the above studies were mostly from a small number of single-point observations, no confirmative conclusions were made on the performance of MODIS PWV products over China. To address this issue, new reference data with good spatial coverage are preferred for the validation of MODIS PWV products. This is the main reason for this study to use both GNSS-PWV and ERA-PWV as references to evaluate the accuracy of MODIS PWV products over China.

Due to some systematic errors contained in MODIS PWV products, it is desirable to perform calibration for correcting or mitigating such errors before the products are used for climatic applications, e.g., the construction of accurate PWV maps based on multi-source data, if a calibration model is available [54,57-59]. The accuracy of MODIS PWV products is dependent upon the performance of the calibration model. The model is usually developed based on the differences between MODIS PWV products and selected reference PWV at co-located ground-based sites, e.g., GNSS stations and/or radiosonde stations, which are the so-called sample data of the modeling. Khaniani et al. [60] used the differences between MOD-NIR-PWV and GNSS-PWV at 38 ground-based GNSS stations over Iran, and a fitting function of height was developed for the calibration model, which effectively reduced the error in MOD-NIR-PWV due to the uniform distribution of the 38 GNSS stations and the slight variation of PWV over Iran. In China, a linear fitting model based on the linear relationship of the differences between MOD-NIR-PWV and reference PWV obtained from other technologies over the whole continent of China is the most common calibration model $[54,55,58]$. The main problem of using the model is that it performs differently in different regions; hence, Liu B. et al. [61] divided China into five regions, and five linear regional models were proposed for linear PWV fitting. However, the performance of the regional models was still not satisfactory due to the low coverage of GNSS stations and the characteristics of strong seasonal variations of the PWV, e.g., large differences between MOD-NIR-PWV and reference PWV in summer and small differences in winter. To consider these two factors, in this study, the ERA5 datasets were adopted as the sample data for better spatial coverage, and a harmonic model fitting the seasonal characteristic of the PWV difference at each ERA5 grid point was established for the calibration model of the grid point. A $0.25^{\circ} \times 0.25$ grid-based calibration model was eventually developed over China.

The outline of this paper is as follows: Various PWV products used in this study are introduced in Section 2. Section 3 presents comprehensive comparisons among PWV products obtained from different techniques over China, followed by the establishment of the grid-based calibration model proposed in this study for the mitigation of the systematic bias in MOD-NIR-PWV in Section 4. Summary and conclusions are given in the last section.

\section{Datasets and Methods}

\subsection{Datasets}

\subsubsection{MODIS}

MODIS is a remote scanning spectroradiometer with 36 discrete spectral bands between 0.645 and $14.235 \mu \mathrm{m}$. PWV from the surface to the upper troposphere is obtained based on the difference of transmittance between the absorption bands (near 0.905, 0.936, and $0.94 \mu \mathrm{m}$ ) and the non-absorption bands (near 0.865 and $1.24 \mu \mathrm{m}$ ) of water vapor [35]. Since MODIS observations are sensitive to clouds in the atmosphere, the cloud-free PWV data in MODIS Level-2 water vapor product from Terra and Aqua (i.e., MOD05 and MYD05) is used in this study with the aid of the MODIS cloud mask product. The MOD05 and MYD05 products consist of two types of PWV data: MOD-NIR-PWV and MOD-IR-PWV. The former, with $1 \mathrm{~km}$ spatial resolution, is available during daytime with a typical error 
level of $5-10 \%$. The latter, with $5 \mathrm{~km}$ spatial resolution, is available during both daytime and nighttime, but its accuracy is poorer than the former. Considering the higher spatial resolution and better accuracy, MOD-NIR-PWV during a six-year period from 2013 to 2018 over China, collected from Level-1 and Atmosphere Archive \& Distribution System (LAADS) Distributed Active Archive Center (DAAC), was used in this study.

It is worth mentioning that different height systems are used for different types of PWV data, e.g., MOD-NIR-PWV refers to the orthometric height, while ERA5 data and radiosonde observations refer to the geopotential, and GNSS observations refer to ellipsoidal heights. In this study, the orthometric height system used in MODIS was treated as the standard. Ellipsoidal heights of GNSS stations, geopotentials of ERA5 atmospheric data and geopotential heights of radiosonde observations were converted into orthometric heights in the following sections.

\subsubsection{ERA5}

ERA5 is the latest generation of the reanalysis dataset from the European Centre for Medium-Range Weather Forecasts (ECMWF), which provides hourly atmospheric profile data at 37 pressure levels from $1000 \mathrm{hPa}$ to $1 \mathrm{hPa}$ over $0.25^{\circ} \times 0.25^{\circ}$ latitude-longitude grids. To adapt to the MOD-NIR-PWV height range, the ERA-PWV used in this study is also referred to the content of PWV from the height of the MODIS pixel to the pressure level of $1 \mathrm{hPa}$.

ERA-PWV can be calculated by integrating atmospheric variables along all pressure levels as defined by [24]:

$$
\operatorname{PWV}_{\mathrm{ERA}}=\frac{1}{\rho_{w}} \int_{1}^{N} \frac{q_{i}}{g_{i}} d P_{i}
$$

where $\rho_{w}$ is the density of liquid water, $g$ is the gravity acceleration (in unit of $\mathrm{m} / \mathrm{s}^{2}$ ), $d P$ is the increment of pressure (in unit of hPa) between two adjacent pressure levels, subscript $i$ denotes the $i$ th pressure level, $N$ is the number of all pressure levels, and $q$ is the specific humidity, which can be obtained from [62]:

$$
\left\{\begin{array}{l}
q=\frac{0.622 P_{v}}{P-0.378 P_{v}} \\
P_{v}=\frac{R H}{100} P_{S} \\
P_{S}=6.112 \exp \left[\frac{17.67\left(T_{C}-273.15\right)}{T_{C}-29.65}\right]
\end{array}\right.
$$

where $P_{v}$ and $P_{s}$ are the partial pressure of water vapor and saturation water vapor pressure (in $\mathrm{hPa}$ ), respectively, $R H$ is the relative humidity, and $T_{C}$ is the Celsius temperature.

To mitigate the error caused by the height difference between an ERA 5 grid point and its corresponding MODIS pixel, the geopotential of each pressure level at the ERA5 grid point was transformed into the orthometric height to unify the two height systems using the following formulas $[63,64]$ :

$$
\left\{\begin{array}{l}
H=E H-H_{\text {geoid }} \\
E H=\frac{R_{\varphi} \cdot H_{g p}}{\frac{g_{\varphi}^{2}}{9.80065} R_{\varphi}-H_{g p}} \\
g_{\varphi}=9.80620 \times\left(1-2.6442 \times 10^{-3} \cos 2 \varphi+5.8 \times 10^{-6} \cos ^{2} 2 \varphi\right) \\
R_{\varphi}=\frac{6378.137}{1.006803-0.006706 \cdot \sin ^{2} \varphi}
\end{array}\right.
$$

where $\varphi$ is the latitude of the grid point, $H, E H$, and $H_{g p}$ are orthometric height (in $\mathrm{km}$ ), ellipsoidal height (in $\mathrm{km}$ ), and geopotential (in $10^{-3} \mathrm{~m}^{2} / \mathrm{s}^{2}$ ), respectively, $H_{\text {geoid }}$ is the geoid height (in km) obtained from Earth Gravitational Model 2008 (EGM2008), and $g_{\varphi}$ and $R_{\varphi}$ are the geoid gravity (in $\mathrm{m} / \mathrm{s}^{2}$ ) and the curvature radius (in $\mathrm{km}$ ) of the Earth at the latitude of $\varphi$, respectively.

Upon the unification of the height systems, atmospheric variables including relative humidity, temperature, and pressure at the height of the MODIS pixel were calculated for 
the final integration. If the MODIS pixel was above the lowest pressure level, the atmospheric variable values for the MODIS pixel were obtained by simple linear interpolation based on the variable values at the two adjacent pressure levels that contain the pixel. If the MODIS pixel was below the lowest pressure level, different strategies for different variables were used: relative humidity was assigned to the constant value, which was the same as that of the lowest pressure level; the temperature was linearly extrapolated based on the temperature value at the lowest pressure level and a constant temperature lapse rate of $6.5^{\circ} \mathrm{C} / \mathrm{km}$; the pressure was calculated from the following hydrostatic and ideal gas equation [65]:

$$
P_{M}=P_{L}^{-\frac{2 g\left(H_{M}-H_{L}\right)}{R_{d}\left(T_{M}+T_{L}\right)}}
$$

where $R_{d}=8.31462$ is the ideal gas constant (in $\mathrm{mol}^{-1} \mathrm{~K}^{-1}$ ), $H_{M}$ and $H_{L}$ denote the orthometric heights of the MODIS pixel and the lowest pressure level of ERA5, respectively, $P_{M}$ and $T_{M}$ are the pressure (in $\mathrm{hPa}$ ) and temperature (in $\mathrm{K}$ ), respectively, at the MODIS pixel, $P_{L}$ and $T_{L}$ are the pressure (in $\mathrm{hPa}$ ) and temperature (in K), respectively, at the lowest pressure level. After this data preprocess was completed, the atmospheric variable values were used in the integral of Equation (1) to obtain the corresponding ERA-PWV from the height of the MODIS pixel to the pressure level of $1 \mathrm{hPa}$.

\subsubsection{Radiosonde}

Radiosonde observations over 78 radiosonde stations were used in this study from the IGRA Version 2 dataset. The geographical distribution of these selected 78 radiosonde stations is shown in Figure 1. The dataset provides various parameters with a temporal resolution of twice a day over China, including pressure, temperature, relative humidity, etc. These derived RS-PWV were calculated based on the same integration method as described in Equation (1). The height match process was also conducted as described in the previous section. After the process, these RS-PWV were used in the performance evaluation of ERA-PWV. It should be noted that RS-PWV was not used in the performance evaluation of MOD-NIR-PWV because of the sparse distribution of radiosonde stations and the large time difference (more than $2 \mathrm{~h}$ ) between the MODIS overpass time and the radiosonde launch epoch.

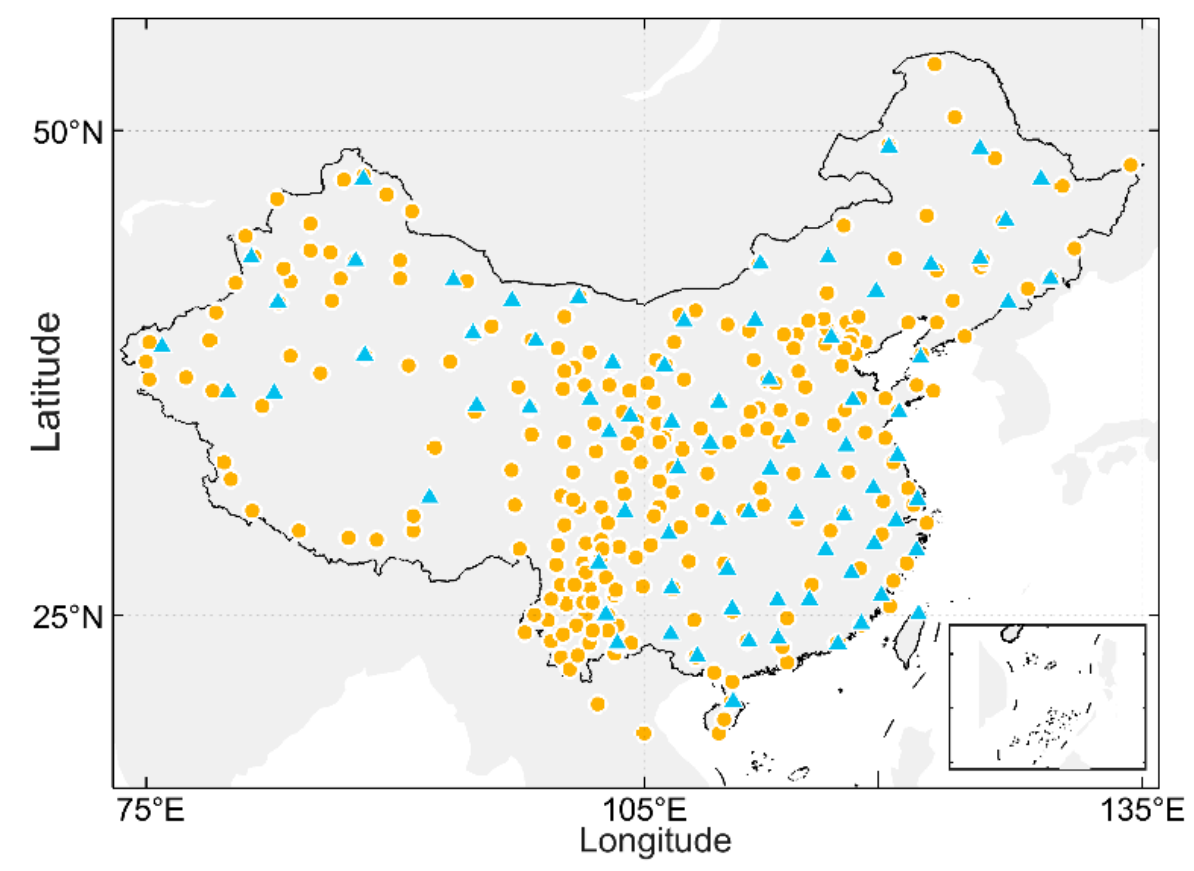

Figure 1. Geographical distribution of 78 radiosonde stations (blue triangle) and 246 ground-based GNSS stations in the CMONOC (orange circle). 


\subsubsection{GNSS}

GNSS-PWV used in this study were retrieved from hourly zenith tropospheric delay (ZTD) during the period from 2013 to 2018 over 246 primary ground-based GNSS stations in the Crustal Movement Observation Network of China (CMONOC) (at http:/ / www. cgps.ac.cn, (accessed on 20 July 2019). The geographical distribution of these 246 stations in Figure 1 indicates a good spatial coverage over most regions in China, i.e., sufficiently dense stations in the central region, but sparse stations in the northeastern region, southeastern region, and the Tibetan Plateau.

In GNSS data processing, for the estimation of unknown parameters, mainly including position and atmospheric errors, etc., the slant tropospheric delay errors contained in those GNSS observations from all the satellites at the same station are projected or mapped onto the station's zenith direction (using a mapping function) to reduce the number of unknown parameters to be solved for. The estimated tropospheric delay error at each station is the zenith tropospheric delay (ZTD), which can be decomposed into zenith hydrologic delay (ZHD) and zenith wet delay (ZWD):

$$
\mathrm{ZTD}=\mathrm{ZHD}+\mathrm{ZWD}
$$

The ZHD can be obtained accurately from a standard model that is a function of the surface meteorological variables of the site. The most commonly used model is the Saastamoinen model as expressed below [66]:

$$
\mathrm{ZHD}=\frac{0.002769 P_{0}}{f\left(\varphi, h_{0}\right)}
$$

where $P_{0}$ is the surface pressure (in $\mathrm{hPa}$ ), $h_{0}$ is the height above geoid (in $\mathrm{km}$ ), and $f\left(\varphi, h_{0}\right)$ is the function given by:

$$
f\left(\varphi, h_{0}\right)=1-0.00266 \cos (2 \varphi)-0.0028 h_{0}
$$

After subtracting the ZHD from the ZTD, what remains is the ZWD, which can be converted to PWV using the following equation $[29,67]$ :

$$
\mathrm{PWV}=\frac{10^{6}}{\rho_{w} R_{w}\left(k_{2}^{\prime}+k_{3} / T_{m}\right)} \mathrm{ZWD}
$$

where $\rho_{w}$ is the density of liquid water, $R_{w}$ is the specific gas constant of water vapor, the two atmospheric refraction constants $k_{2}^{\prime}=16.52 \mathrm{k}^{2} / \mathrm{hPa}$ and $k_{3}=3.776 \times 10^{5} \mathrm{k}^{2} / \mathrm{hPa}$, $T_{m}$ is the atmospheric weighted mean temperature, and its definition (by the following integral) as well as approximation (the summation) is:

$$
T_{m}=\frac{\int \frac{P_{v}}{T} d z}{\int \frac{P_{v}}{T^{2}} d z} \approx \frac{\sum_{i=1}^{N-1} \frac{P_{v, i}}{T_{i}} \Delta z_{i}}{\sum_{i=1}^{N-1} \frac{P_{v, i}}{T_{i}^{2}} \Delta z_{i}}
$$

where $T$ is the atmospheric temperature (in Kelvin) along the vertical direction of the site, $d z$ is the incremental step $\Delta z$ is the difference between the heights of the two adjacent pressure levels (in meters).

Equations (6)-(9) indicate that meteorological data are essential in the conversion of GNSS-ZTD into PWV. However, some GNSS stations are neither equipped with meteorological sensors nor co-located with a radiosonde station that can provide such measurements. In this case, the only way is to use assimilated values from the reanalysis dataset from NWP models (e.g., ERA-Interim and ERA5) for the conversion. Considering the consistency of these atmospheric data, ERA5 reanalysis data rather than meteorological measurements were used in this study. After the atmospheric variable values at the position of the GNSS 
antenna are calculated from the procedure introduced in Section 2.1.2, $T_{m}$ and ZHD can be

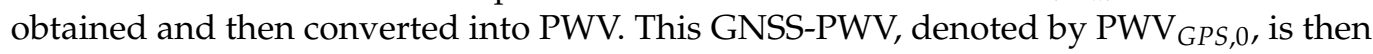
corrected to the height of each MODIS pixel, denoted by $\operatorname{PWV}_{G P S, M}$, using the vertical correction function below:

$$
\mathrm{PWV}_{G P S, f}=\mathrm{PWV}_{G P S, 0} e^{\lambda\left(E H-H_{\text {geoid }}-H_{M}\right)}
$$

where $P W V_{G P S, 0}$ and PWV $V_{G P S, M}$ are in millimeters, $E H$ and $H_{M}$ are the ellipsoidal height and orthometric height of the GNSS antenna and MODIS pixel, respectively, and the constant $\lambda=0.439$ is the water vapor lapse rate given by [68].

\subsection{Statistical Metrics}

Three statistical metrics were used to evaluate the performance of MOD-NIR-PWV in this study. They were bias, root-mean-squared (RMS), and correlation coefficient (r) and their definitions are listed below:

$$
\begin{gathered}
\text { Bias }=\frac{\sum_{i=1}^{n} \mathrm{PWV}_{e, i}-\mathrm{PWV}_{r, i}}{n} \\
R M S=\sqrt{\frac{\sum_{i=1}^{n}\left(\mathrm{PWV}_{e, i}-\mathrm{PWV}_{r, i}\right)^{2}}{n}} \\
r=\frac{\sum_{i=1}^{n}\left(\mathrm{PWV}_{e, i}-\overline{\mathrm{PWV}}_{e}\right)\left(\mathrm{PWV}_{r, i}-\overline{\mathrm{PWV}}_{r}\right)}{\sqrt{\sum_{i=1}^{n}\left(\mathrm{PWV}_{e, i}-\overline{\mathrm{PWV}}_{e}\right)^{2} \sum_{i=1}^{n}\left(\mathrm{PWV}_{r, i}-\overline{\mathrm{PWV}}_{r}\right)^{2}}}
\end{gathered}
$$

In Equations (11)-(13), the subscriptions $e$ and $r$ denote "evaluated" and "reference", respectively, $\overline{\mathrm{PWV}}_{e}$ and $\overline{\mathrm{PWV}}_{r}$ are the mean values of $\mathrm{PWV}_{e}$ and $\mathrm{PWV}_{r}$, respectively, of all the samples, and $n$ is the number of PWV samples.

\section{Evaluation Results}

In this section, the accuracy of ERA-PWV over China is firstly evaluated using GNSSPWV and RS-PWV as reference data; then, the performance and the systematic discrepancies of MOD-NIR-PWV relative to both GNSS-PWV and ERA-PWV are evaluated. Finally, a grid-based calibration model is proposed based on the differences between MOD-NIR-PWV and ERA-PWV.

\subsection{Geographical Distribution of PWV over China}

Figure 2 shows the geographical distribution of the mean PWVs calculated from the ERA-PWV in a period from 2013 to 2018 over China. PWV values over China present a relationship with the geographical location: a clear decline from the southeastern coastal region to the northwestern inland region. The variation tendency is consistent with the result in Gui [49] and Zhang [46].

The maximum value was found in the southeastern coastal region with a mean PWV greater than $40 \mathrm{~mm}$, which was mainly due to its moist condition. The mean PWVs over central China varied from 15 to $30 \mathrm{~mm}$. In the southwestern regions, the mean PWVs were affected by the topography, in particular, the Tibetan Plateau with the highest elevation presented the lowest mean PWVs (about $5 \mathrm{~mm}$ ). In the northwestern inland region with dry conditions, PWV values remained at a low level in the range from 5 to $15 \mathrm{~mm}$. The PWVs in the northeastern regions also presented low values ranging from 10 to $15 \mathrm{~mm}$ due to the high latitude and the effect of the winter monsoon. 


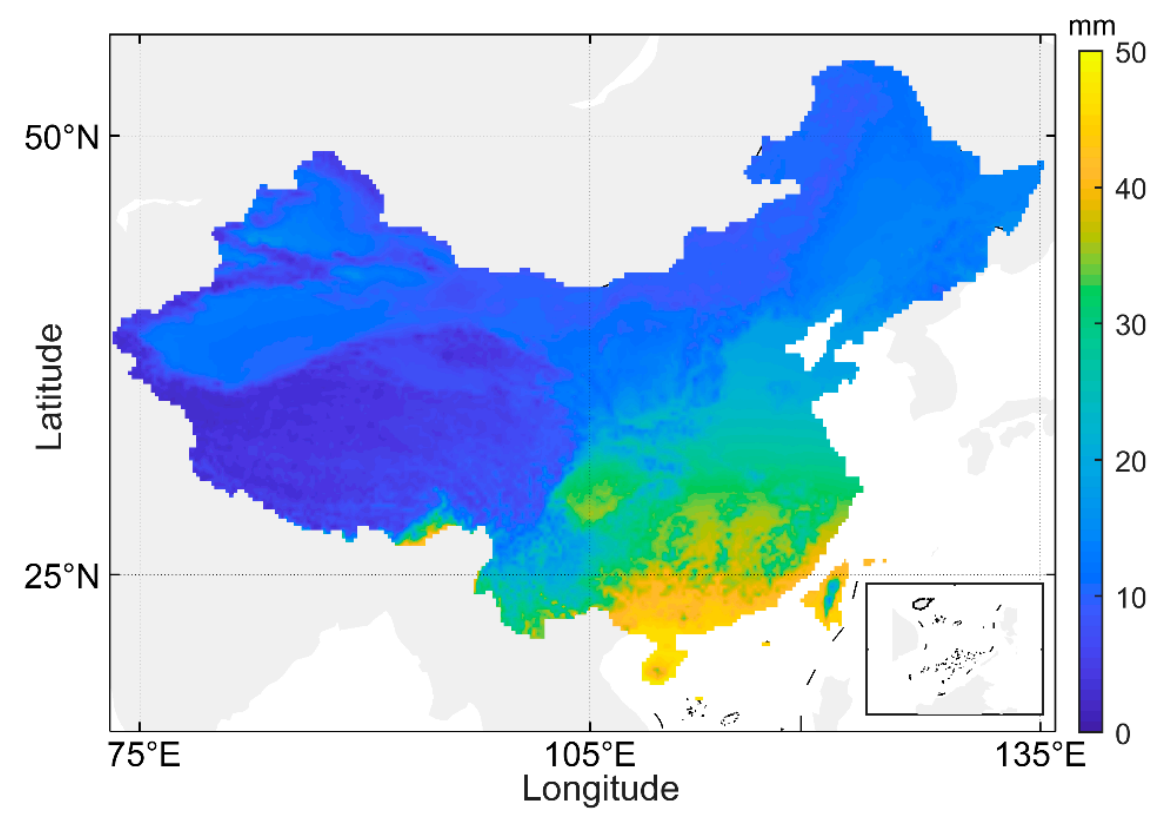

Figure 2. Mean PWV (millimeters) calculated from the ERA-PWV in the six-year period from 2013 to 2018 over China.

\subsection{Evaluation of ERA-PWV}

\subsubsection{Comparison between GNSS-PWV and ERA-PWV}

The hourly GNSS-PWV at the aforementioned 246 GNSS stations (see Figure 1) is in a different form from the hourly ERA-PWV, i.e., single-point and two-dimensional gridded observations. The comparisons between the two types of data needed to be made over the same points. Therefore, ERA-PWV at a given GNSS station was obtained from an inverse distance weighting interpolation of the ERA-PWV values at the four grids surrounding the GNSS station in this study.

The statistical result of the differences between GNSS-PWV and ERA-PWV in the six-year period from 2013 to 2018 over each of the selected 246 GNSS stations is shown in Figure 3. The biases at all GNSS stations were in the range from -2.0 to $3.2 \mathrm{~mm}$ with a mean value of $0.5 \mathrm{~mm}$. The positive bias values at 167 stations imply that ERA-PWV were slightly overestimated. The correlation coefficient values were in the range of 0.959-0.997, which were considerably high, meaning that the temporal variation between GNSS-PWV and ERA-PWV was consistent. As for the RMSs, the minimum, maximum, and mean of the RMSs at all stations were $0.8,4.1$, and $1.7 \mathrm{~mm}$, respectively. The largest RMS was at the SCSM station (latitude $29.2^{\circ} \mathrm{N}$, longitude $102.4^{\circ} \mathrm{E}$ ) in Sichuan province close to the Tibetan Plateau. In addition, the RMS values seemed to be geographical location-dependent: the values gradually decreased from the southeastern coastal region to the northwest inland region. This decreasing trend was related to the nature of the regional climate, i.e., the tropical monsoon climate in the southeastern coastal region, the humid continental climate in the northwestern inland region, and the plateau climate in the Tibetan Plateau.

Figure 4 shows the distribution, represented by the frequency (in percentage) of data falling into each of the predefined ranges, of the differences between two of the three sets of PWV over the same six-year period. It is noted that GNSS-PWV and RSPWV are based on single-point results, while ERA-PWV is based on the entire gridded points. The total frequency accumulated in the first five ranges, which are negative data, was $37 \%$ for the difference between GNSS-PWV and ERA-PWV, and about $86 \%$ of the differences concentrate in the range from -2 to $3 \mathrm{~mm}$. The distribution means a slight overestimation of ERA-PWV. A normal distribution shown by all the blue bars implies that the discrepancies between the two sets of PWV were not systematic biases, which also means a good agreement between the two sets of PWV. 

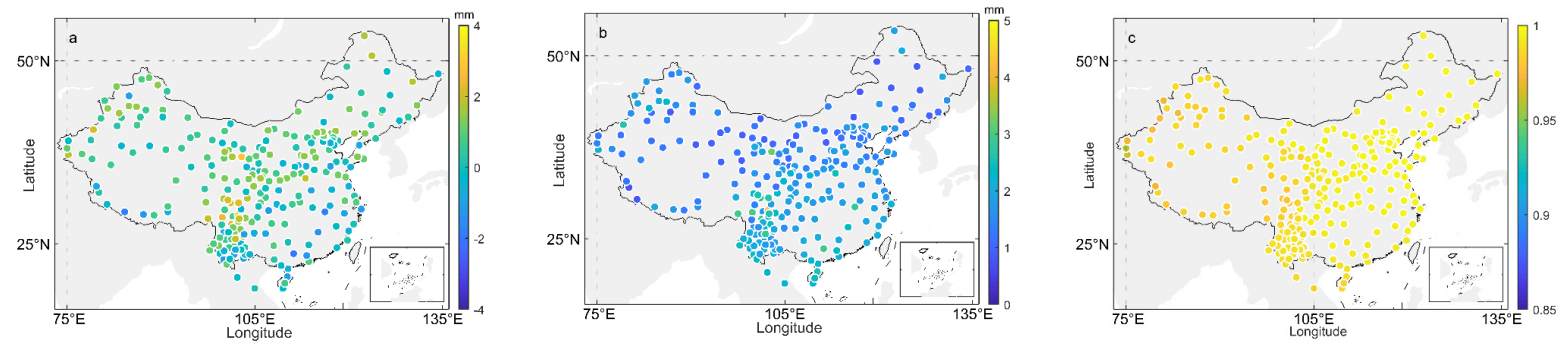

Figure 3. (a) Bias, (b) RMS, and (c) correlation coefficient between GNSS-PWV and ERA-PWV in the six-year period studied from 2013 to 2018 over each of the 246 GNSS stations.

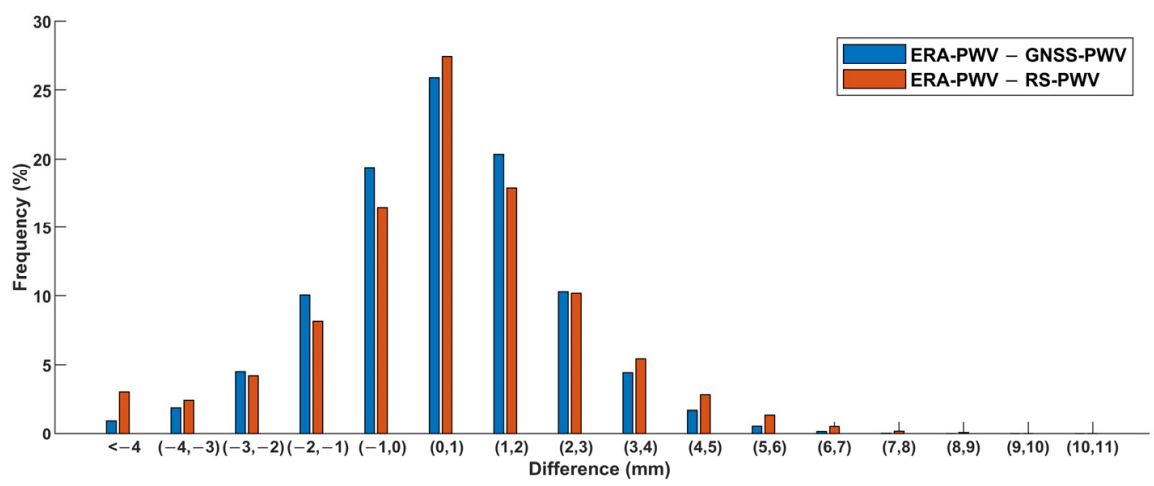

Figure 4. Distribution of the differences (in millimeters) between GNSS-PWV, RS-PWV, and ERAPWV in the six-year period studied from 2013 to 2018 over China.

\subsubsection{Comparison between RS-PWV and ERA-PWV}

The RS-PWV at 78 radiosonde stations in the six-year period from 2013 to 2018 was used as another reference to evaluate the performance of the ERA-PWV over China. The inverse distance weighting interpolation was also conducted to release the non-co-location problem in the spatial domain between the single-point RS-PWV and two-dimensional ERA-PWV.

The statistical result of the differences between GNSS-PWV and ERA-PWV over each radiosonde station is shown in Figure 5. The minimum, maximum, and mean values of the biases at these radiosonde stations were $-3.0,2.2$ and $0.4 \mathrm{~mm}$, respectively. The RMSs varied from 0.5 to $4.2 \mathrm{~mm}$ with a mean value of $1.9 \mathrm{~mm}$. The biases and RMSs were similar with those referring to GNSS-PWV, indicating the equivalent accuracy between RS-PWV and GNSS-PWV over China. The correlation coefficients between RS-PWV and ERA-PWV were in the range from 0.897 to 0.990 , and the mean correlation coefficient was 0.970 . The extremely low correlation coefficient values were distributed in northeastern regions of the Tibetan Plateau, which may be attributed to the poor reliability of ERA-PWV over complex terrain. In addition, about $34 \%$ of the differences between ERA-PWV and RS-PWV were accumulated in the negative ranges (see Figure 4). The apparent normal distribution of the differences in Figure 4 indicated no obvious systematic discrepancy between ERA and RS.
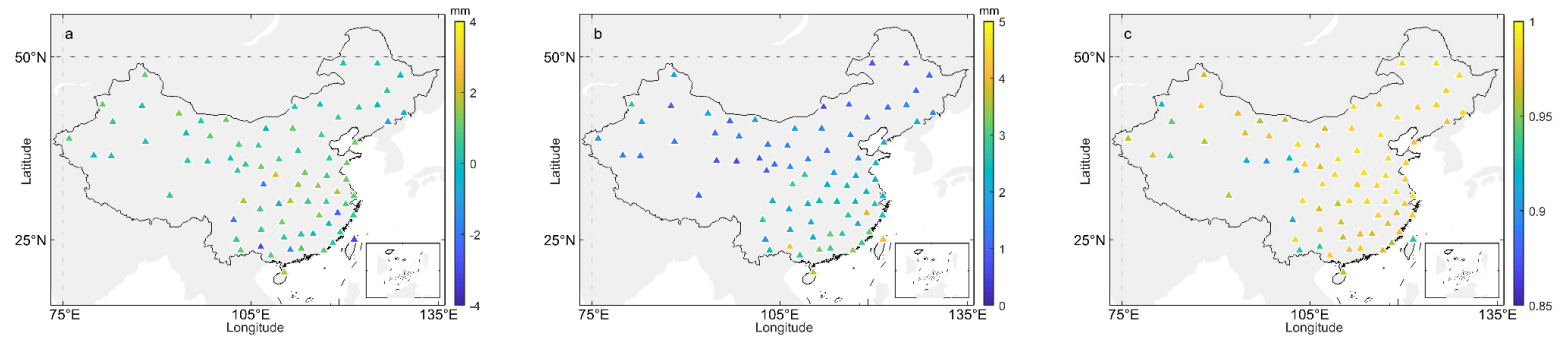

Figure 5. (a) Bias, (b) RMS, and (c) correlation coefficient between RS-PWV and ERA-PWV in the six-year period studied from 2013 to 2018 over each of the 78 radiosonde stations. 
These results referring to GNSS-PWV and RS-PWV agree well with each other, implying the perfect accuracy of ERA-PWV over China. Therefore, ERA-PWV can be used as a new reference for the evaluation of MOD-NIR-PWV due to its better spatial continuity and coverage.

\subsection{Evaluation of MOD-NIR-PWV}

\subsubsection{Comparison between GNSS-PWV and MOD-NIR-PWV}

Since MOD-NIR-PWV and GNSS-PWV are not spatially co-located, a spatial interpolation process is needed to make the former co-located with the latter. Both sets of PWV are also not simultaneous observations in the temporal domain, i.e., the overpass time of the MODIS over a GNSS station differs from the epoch of any hourly GNSS-PWV, thus, preprocessing for the selection of the GNSS-PWV that adapts to the overpass time of the MODIS needs to be performed. In this study, the mean of the GNSS-PWV at four consecutive epochs, two of which were immediately before the MODIS overpass and the other two were immediately after the overpass, was used in the later comparison for addressing the simultaneity problem. In the spatial domain, a vertical correction for GNSS-PWV and a horizontal interpolation for MOD-NIR-PWV were conducted to reduce the effects caused by the height difference and non-co-location, respectively, between the GNSS station and MODIS pixel. More specifically, for a given GNSS station, the optimal height of the corresponding MODIS image was determined from the inverse distance interpolation of the heights of nine MODIS pixels in a $3 \times 3$ pixel window centered at the GNSS station. Then, to match the optimal MODIS height, the GNSS-PWV over the station obtained from the mean value of consecutive four epochs was corrected based on Equation (10) and named as corrected GNSS-PWV. For MOD-NIR-PWV, i.e., in the horizontal domain, the inverse distance weighted interpolation of MOD-NIR-PWV data of the same $3 \times 3$ pixel window was performed for its final result, which was compared to the above corrected GNSS-PWV. It is noted that 25 GNSS stations were discarded because their MOD-NIR-PWV time series were less than $20 \%$ of the six-year period studied. The statistical metrics for the differences between the two sets of PWV over each of the 221 GNSS stations are shown in Figure 6.
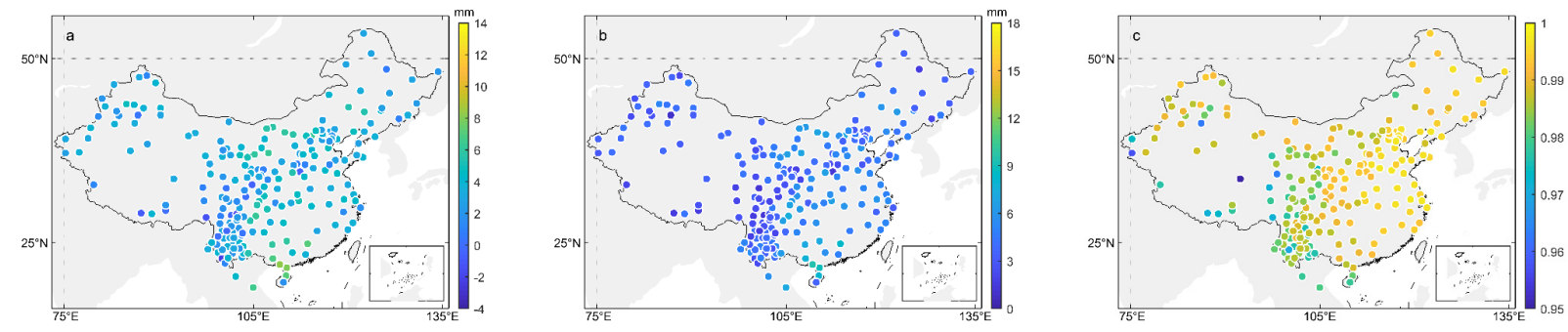

Figure 6. (a) Bias, (b) RMS, and (c) correlation coefficient between GNSS-PWV and MOD-NIR-PWV in the six-year period studied from 2013 to 2018 over each of the 221 GNSS stations.

It can be seen that both the biases and RMSs were considerably large, while the correlation coefficient values were small, especially in the southeastern coastal region. Overall, the bias of each GNSS station varied from -1.2 to $8.3 \mathrm{~mm}$ with a mean value of $2.9 \mathrm{~mm}$, and biases at 215 stations were positive. The RMSs were in the range from 0.9 to $9.4 \mathrm{~mm}$ with a mean value of $3.8 \mathrm{~mm}$. The biases and RMSs indicate the poor performance of MOD-NIR-PWV over China. Moreover, some relatively higher biases ( $>5 \mathrm{~mm}$ ) and RMSs $(>6 \mathrm{~mm})$ were observed in the southeastern coastal region, which suggests the much poorer performance of MOD-NIR-PWV. A similar decreasing trend of the biases and RMSs from the southeast to the northwest was also noticeable. Additionally, the minimum, maximum, and mean of the correlation coefficient values were $0.954,0.998$, and 0.991 , respectively, implying similar temporal variation trends between the two sets of PWV. This indicates the potential to improve the precision of MOD-NIR-PWV throughout some calibrations. 
The non-normal distribution shown by the red bars in Figure 7 indicates that the differences between MOD-NIR-PWV and GNSS-PWV were systematic biases. Moreover, the total frequency in the five ranges, i.e., the frequency of negative differences, was less than $11 \%$; about $66 \%$ of the differences were concentrated in the range between 0 and $4 \mathrm{~mm}$, implying that the large systematic biases were due to the significant overestimation of MOD-NIR-PWV. This result is consistent with the findings from the comparisons with radiosonde data in Hongkong by Liu Z. et al. [13] and also in mainland China by Liu H. et al. [54]. However, a more confirmative conclusion needs to be made based on more comparisons with spatially continuous reference data such as ERA-PWV to evaluate the performance of MOD-NIR-PWV over China. This will be discussed in the next section.

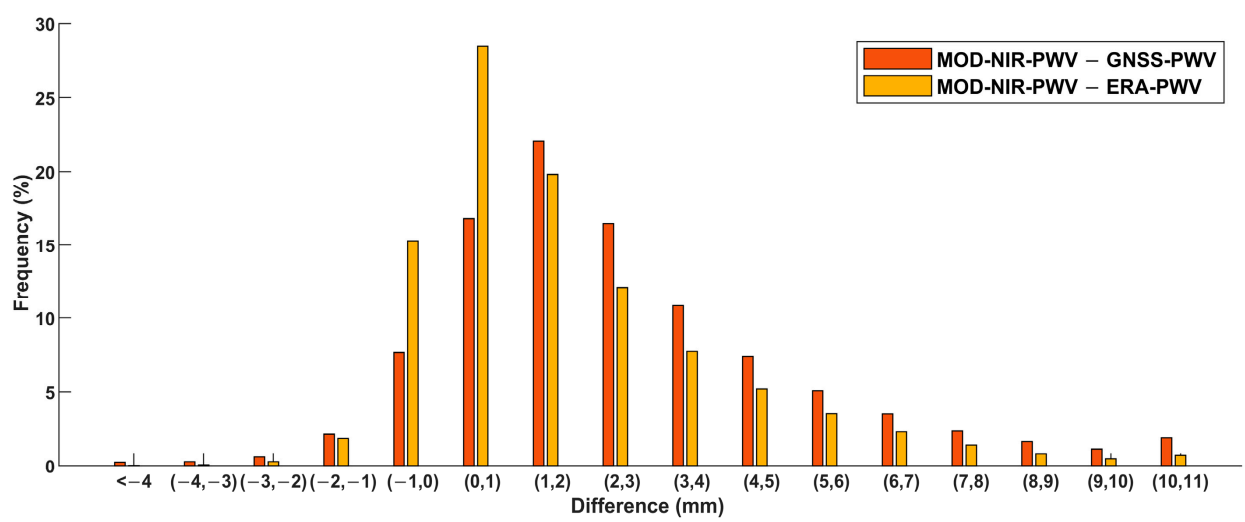

Figure 7. Distribution of the differences (in millimeters) between GNSS-PWV, ERA-PWV, and MOD-NIR-PWV in the six-year period studied from 2013 to 2018 over China.

\subsubsection{Comparison between ERA-PWV and MOD-NIR-PWV}

The high accuracy of ERA-PWV has been validated using GNSS-PWV as the reference over China in Section 3.2, hence, ERA-PWV was used as the reference of MOD-NIR-PWV in this section. The two sets of data also needed to be preprocessed for a valid comparison, i.e., the two types of datasets needed to correspond to the same position and also the same time. In this study, the $3 \times 3$ pixel window algorithm was adopted to determine the MOD-NIR-PWV values for the position of the ERA-5 grid points in the MODIS image, and the four-consecutive-epoch interpolation was used to solve the problem of the mismatch in the temporal domain, as described in the previous section. Figure 8 shows the statistical results of the comparison between ERA-PWV and MOD-NIR-PWV in the same six-year period studied. Note that a few grid points show white color, meaning lack of values, the reasons for which were (1) MODIS sensors being sensitive to sunlight (only MOD-NIR-PWV in the bright land is available) and (2) the lengths of the MOD-NIR-PWV time series at the grid points being not sufficient for a reasonable statistic result.
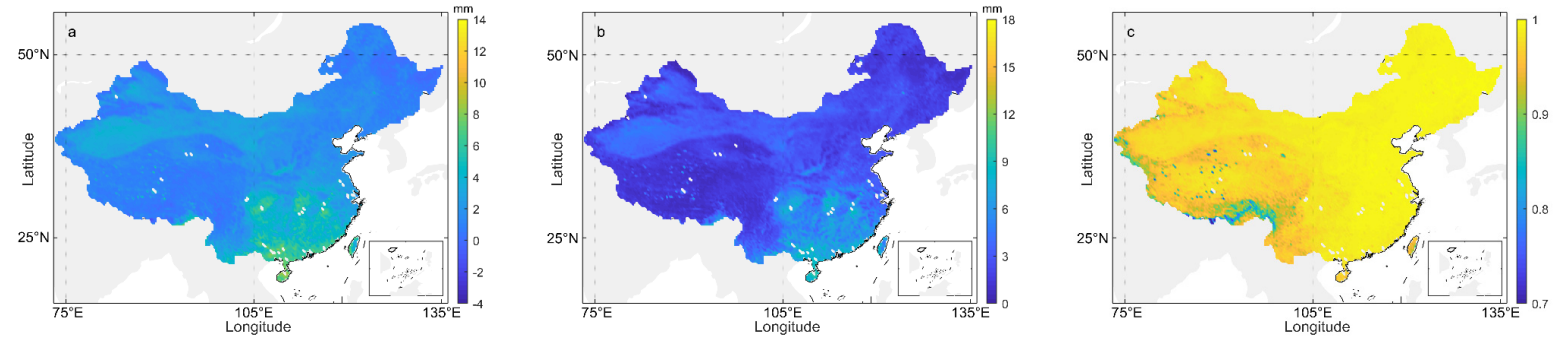

Figure 8. (a) Bias, (b) RMS, and (c) correlation coefficient between ERA-PWV and MOD-NIR-PWV in the six-year period from 2013 to 2018 over each grid point. 
As shown in Figure 8a, the most positive bias values mean the general overestimation of the MOD-NIR-PWV in comparison with the ERA-PWV. The biases were mostly in the range from -0.6 to $8.2 \mathrm{~mm}$ with a mean value of $2.1 \mathrm{~mm}$. Most RMS values (see Figure $8 \mathrm{~b}$ ) were in the range from 0.7 to $10.0 \mathrm{~mm}$ with a mean value of $3.0 \mathrm{~mm}$. It is clear that poor results were from the regions under a relatively humid climate condition, such as mid-latitude and southeastern coastal regions, especially in Hainan Province, the island in southeastern China where the maximum biases and RMSs were above 7 and $9 \mathrm{~mm}$, respectively. Moreover, both biases and RMSs had similar variation trends: they increased with increasing amounts of PWV from the southeastern coastal region to the northwestern inland region. The overall correlation coefficient values in Figure $8 \mathrm{c}$ varied largely, from 0.616 to 0.998 with a mean of 0.975 , which was different from the comparison with GNSS-PWV discussed in the above section. In contrast to the high variation in biases and RMSs, the correlation coefficient values showed slight variation in most regions, but abnormally low values $(<0.8)$ occurred on some grid points in the Tibetan Plateau and southwestern region.

The frequency distribution shown in yellow bars in Figure 7 also indicates the nonnormal feature of the differences between ERA-PWV and MOD-NIR-PWV. The frequency of negative differences (about 17\%) was significantly lower than that in all of the other ranges, which accounted for over $83 \%$ of all the differences. Moreover, about $76 \%$ of the differences were concentrated in the range from -1 to $3 \mathrm{~mm}$. These results confirm the considerable systematic overestimation of MOD-NIR-PWV over China.

The distributions of seasonal biases and RMSs were also compared; see Figures 9 and 10, which show little seasonal differences in the Tibetan Plateau, thus, the Tibetan Plateau was discarded in the following investigation. Apart from the Tibetan Plateau, all the other regions showed distinctive seasonal differences: the lowest biases and RMSs were all found in winter in all regions with means of 0.7 and $1.2 \mathrm{~mm}$, respectively, while the highest values occurred in summer or autumn in different regions. In most of these regions, except for the southwestern region, the highest values were found in the summer, mainly due to the dramatic wet bias of MODIS sensors in monsoon seasons. In summer, a large amount of water vapor is continuously transported into inland regions from the western Pacific Ocean by the East Asian monsoon, leading to an increase in PWV in eastern China. These continuous wet conditions result in relatively high wet bias and bad statistical results. In winter, dry and cool conditions caused by the air-flow pattern of the winter monsoons lead to the low biases in MOD-NIR-PWV. Therefore, relatively better agreement is found in winter in these regions. This comparison confirms that the wet conditions in summer are the main reason for the significant systematic bias between MOD-NIR-PWV and the references (including GNSSPWV and ERA-PWV). In the southwestern region, the highest value occurred in autumn. This phenomenon may be related to few synoptic stations deployed in these regions, which further affects the accuracy of the ERA5 dataset. 


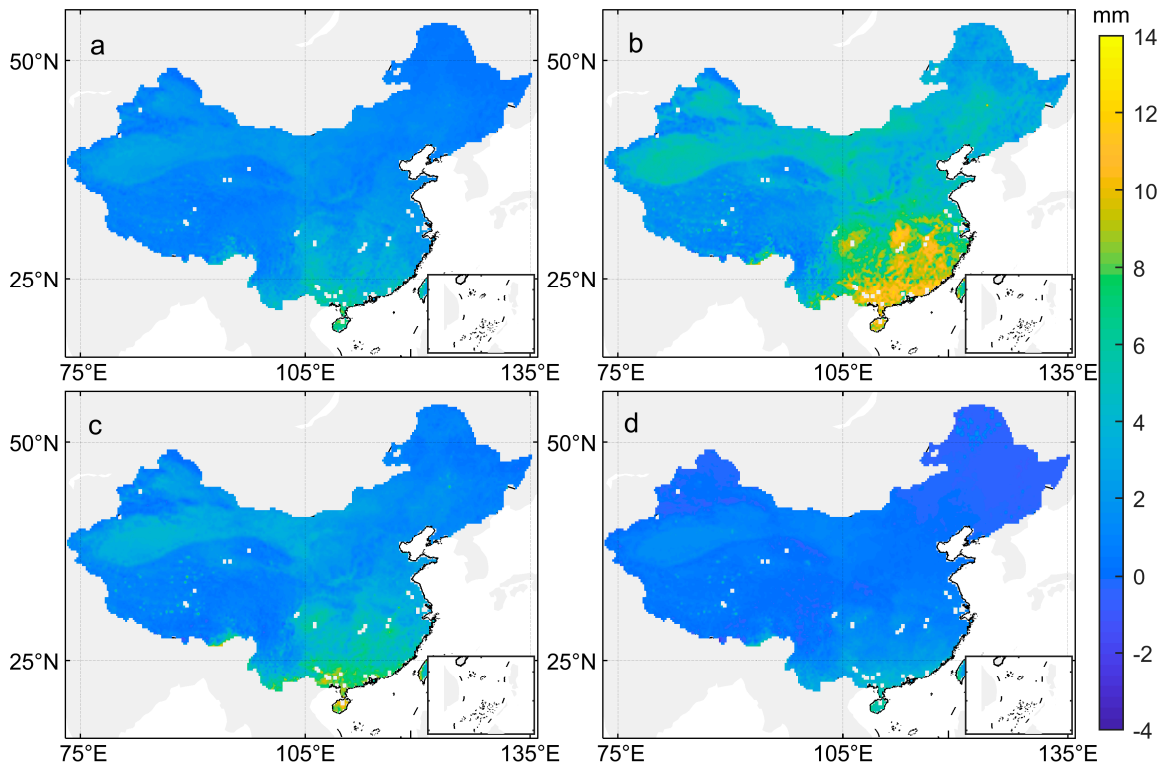

Figure 9. Distribution of seasonal biases between ERA-PWV and MOD-NIR-PWV in the six-year period studied over each grid point in (a) spring, (b) summer, (c) autumn, and (d) winter.
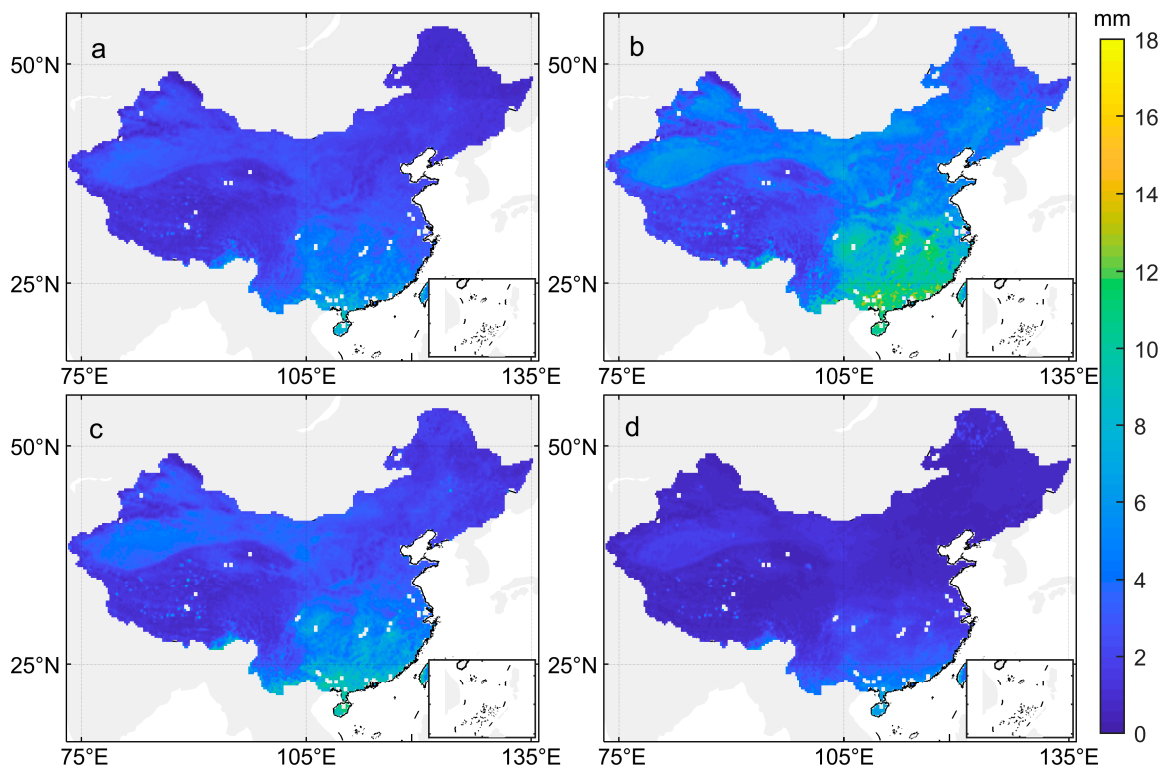

Figure 10. Distribution of seasonal RMSs between ERA-PWV and MOD-NIR-PWV in the six-year period studied over each grid point in (a) spring, (b) summer, (c) autumn, and (d) winter.

\section{Grid-Based Calibration Modeling for MOD-NIR-PWV}

One of the main aims of this study was to mitigate systematic biases in the MODIS water vapor products over China. GNSS-PWV and ERA-PWV are the two types of reference data to calibrate these biases. Several studies used the difference between MOD-NIR-PWV and GNSS-PWV as sample data to achieve it $[53,54,57,61]$. However, the relationship between GNSS PWV and MOD-NIR-PWV in different geographical locations is different, thus, the performance of these calibration models may perform differently in different regions, especially in the regions where only a few GNSS stations are deployed (see Figure 6c). To have consistent calibration performance, the differences between ERA-PWV and MOD-NIR-PWV in the six-year period at each grid point were used as the sample data to develop a grid-based calibration model due to the better spatial coverage and 
continuity of ERA-PWV in comparison with those of GNSS-PWV. As a result, the difference between the original MOD-NIR-PWV and the calibrated (or corrected) MOD-NIR-PWV was in fact the residual of the calibration model which represents the internal agreement (i.e., precision) of the samples used in the modeling process. In addition, the accuracy of the model was also evaluated by comparing the calibrated MOD-NIR-PWV against the reference of the GNSS-PWV at all the 221 stations in the same six-year period, which were out-of-sample data. This can be considered as an indication of external agreement (i.e., accuracy). The reason for the use of the same six-year period (2013-2018) GNSS-PWV as the test data, rather than the follow-up of one or two years (2019-2020) was that the amount of available MOD-NIR-PWV in the two years was insufficient for a sound statistical result.

Although the seasonal biases and RMSs at all grids have been shown in Figures 9 and 10, for clearer comparisons, the seasonal differences at four randomly selected grid points are extracted and shown in Table 1. The periodic characteristics of the differences in the six-year period studied at the four points were also analyzed using the Lomb-Scargle periodogram method [69], and results are shown in Figure 11.

Table 1. Geographical location, seasonal bias, and RMS in the six-year period studied at each of four randomly selected grid points.

\begin{tabular}{ccccccccccc}
\hline \multirow{2}{*}{$\begin{array}{c}\text { Latitude } \\
\left({ }^{\circ}\right)\end{array}$} & \multirow{2}{*}{$\begin{array}{c}\text { Longitude } \\
\left({ }^{\circ}\right)\end{array}$} & \multirow{2}{*}{$\begin{array}{c}\text { Mean PWV } \\
(\mathbf{m m})\end{array}$} & \multicolumn{4}{c}{ Bias $(\mathbf{m m})$} & \multicolumn{3}{c}{ RMS (mm) } \\
\cline { 5 - 10 } & & & Spring & Summer & Autumn & Winter & Spring & Summer Autumn & Winter \\
\hline 30 & 87 & 3.6 & 0.6 & 1.0 & 0.4 & 0.2 & 0.8 & 1.2 & 0.7 & 0.5 \\
40 & 81 & 12.1 & 3.2 & 5.7 & 4.3 & 1.6 & 3.8 & 6.4 & 4.8 & 1.9 \\
36 & 113 & 15.0 & 1.3 & 4.4 & 1.9 & 0.4 & 2.0 & 4.8 & 2.6 & 0.9 \\
22.25 & 114 & 42.7 & 1.4 & 6.5 & 5.9 & 2.9 & 3.5 & 8.1 & 7.4 & 3.9 \\
\hline
\end{tabular}

The differences shown in the left column in Figure 11 indicate clear annual and semiannual periodicities at all four grid points, and the periodograms in the right column also illustrate the most notable components in the differences. Based on this characteristic, a harmonic regression model that contained annual and semiannual periodicities and fitted the differences of the two sets of PWV at a given grid point was constructed for the point. The model was:

$$
y(t)=y_{0}+v \cdot t+c_{1} \cos (2 \pi t)+s_{1} \sin (2 \pi t)+c_{2} \cos (4 \pi t)+s_{2} \sin (4 \pi t)+\varepsilon
$$

where $y$ is the difference, i.e., MOD-NIR-PWV-ERA-PWV (in millimeters) at the point, $t$ is the epoch (in unit of year), $y_{0}$ is the constant intercept, $v$ is the slope, $c_{1}$ and $s_{1}$ are the sine and cosine coefficients for the annual period, respectively, $c_{2}$ and $s_{2}$ are the sine and cosine coefficients for the semiannual period, respectively, and $\varepsilon$ is the fitting residual of the model.

All unknown parameters were estimated from the least-squares method and the sample difference data at the grid point. Different grid points had different fitting models as different sample data were used. These models for all $0.25^{\circ} \times 0.25$ grids formed a grid-based model, which was used to predict the difference value at any target point as a correction of the MOD-NIR-PWV on the point. It should be noted that if the target site was one of the grid points, then the predicted difference (or correction) value could be directly obtained from the model of the grid point. However, for any non-grid point, its predicted correction value was obtained from an interpolation of the model-predicted values at the four grid points surrounding the target point.

To evaluate the performance of the constructed calibration model, all the original MOD-NIR-PWV during the six-year period studied were calibrated at first, then, the differences of the calibrated MOD-NIR-PWV compared to both ERA-PWV and GNSS-PWV were used to measure the precision and accuracy of the model, respectively. Their statistical results are shown in Figures 12 and 13, and the frequency distribution of the differences between the calibrated MOD-NIR-PWV and the two sets of reference data over the same 
six-year period studied is shown in Figure 14. It is worth mentioning that Figure 12 shows spatially continuous data (except for a few white or blank points), while Figure 13 shows discrete points, because ERA-PWV and GNSS-PWV are from regular grid points and non-regular (i.e., non-grid) points, respectively.
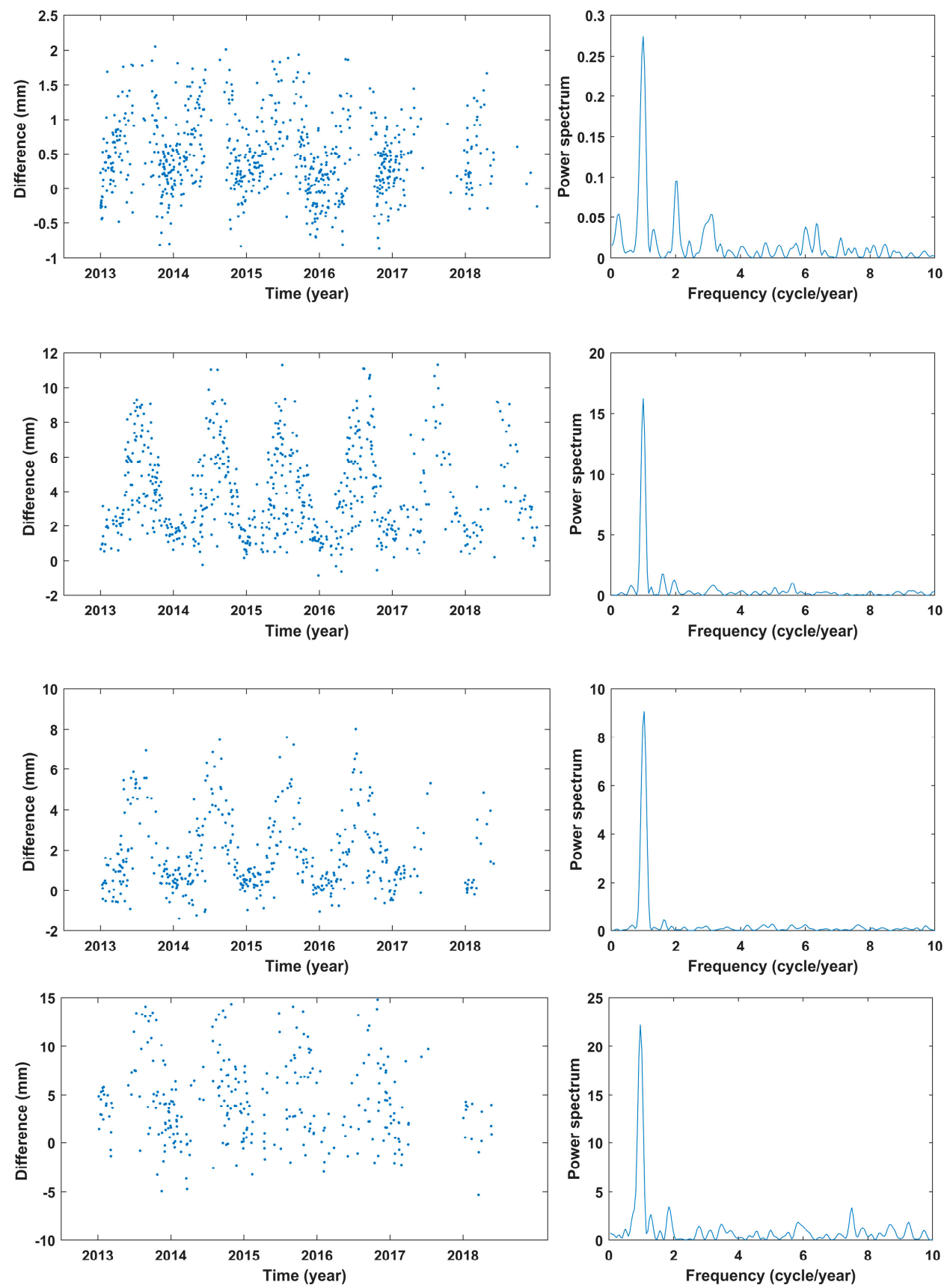

Figure 11. Difference (in millimeters) between ERA-PWV and MOD-NIR-PWV (left) during the six-year period studied at four randomly selected grid points, and their Lomb-Scargle periodograms (right). 

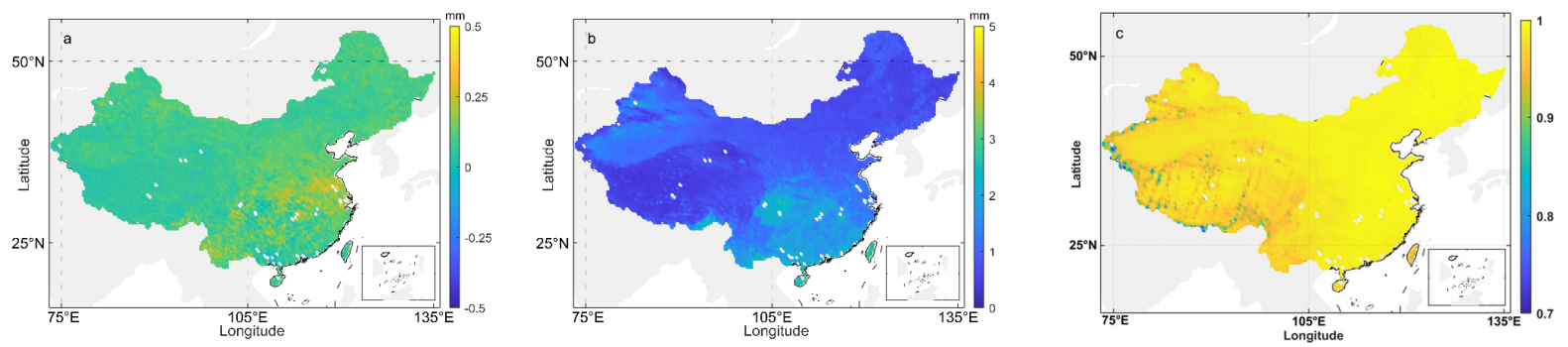

Figure 12. (a) Bias, (b) RMS, and (c) correlation coefficient between ERA-PWV and calibrated MOD-NIR-PWV in the six-year period studied over each grid point.
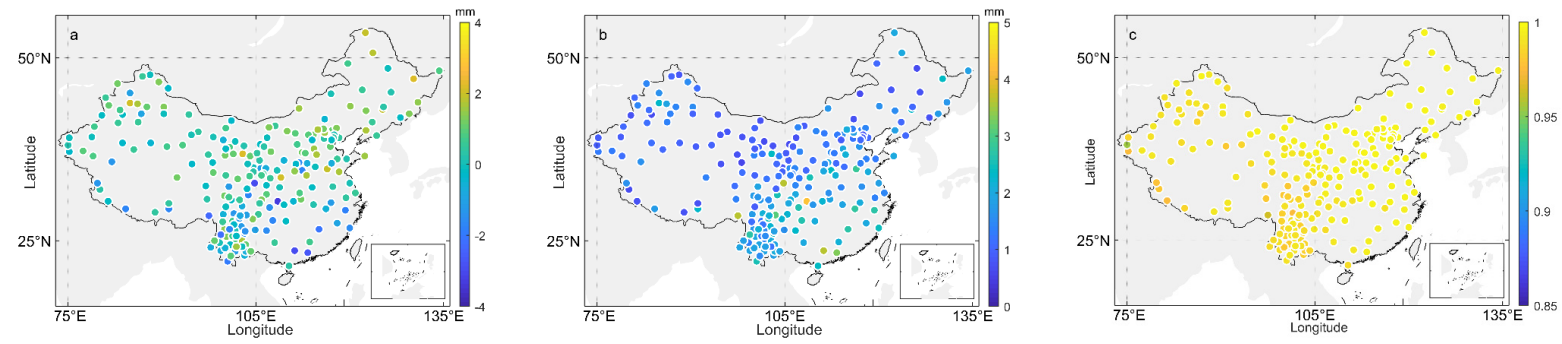

Figure 13. (a) Bias, (b) RMS, and (c) correlation coefficient between GNSS-PWV and calibrated MOD-NIR-PWV in the six-year period studied over each site of the 221 GNSS stations.

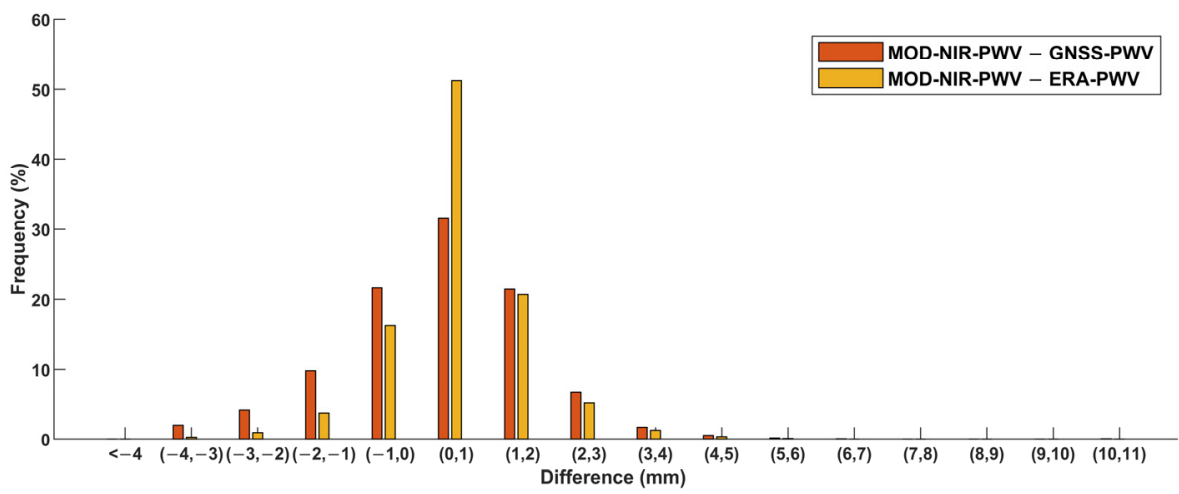

Figure 14. Distribution of the differences (in millimeters) between GNSS-PWV, ERA-PWV, and calibrated MOD-NIR-PWV in the six-year period studied over China.

From Figure 12, the calibrated MOD-NIR-PWV had a better agreement with ERAPWV than the original MOD-NIR-PWV over China, which was reasonable, since the calibration model at each grid point was based on the differences of ERA-PWV and MODNIR-PWV at the point. After the calibration, the minimum, maximum, and mean biases were $-0.2,0.5$ and $0.1 \mathrm{~mm}$, respectively; the corresponding values of RMSs were $0.2,4.6$ and $1.0 \mathrm{~mm}$, respectively. The biases and RMSs were reduced by $94 \%$ and $71 \%$, respectively, compared to those of the original MOD-NIR-PWV, especially in the southeastern coastal region. The calibration also had significant positive effects on the correlation coefficients in the southwestern region, but little effects in the other regions. In addition, the normal distribution of the yellow bars in Figure 14 also indicates the effectiveness in the reduction of the systematic biases of MOD-NIR-PWV at the GNSS stations. Therefore, the constructed calibration model had good precision.

In Figure 13, the bias values were in the range from -3.4 to $2.2 \mathrm{~mm}$, and the minimum bias of $-3.4 \mathrm{~mm}$ was further away from zero, compared to the original minimum bias of $-1.2 \mathrm{~mm}$, and the frequency accumulated in negative ranges was higher than that between GNSS-PWV and original MOD-NIR-PWV. However, the distribution of the differences was more consistent with a normal distribution (see Figure 14), and most differences were 
concentrated in the range from -1 to $2 \mathrm{~mm}$, resulting in smaller systematic biases of the calibrated MOD-NIR-PWV. Moreover, the RMSs were decreased by $53 \%$ with a smaller range from 0.6 to $4.3 \mathrm{~mm}$, and the correlation coefficient values showed slight variation due to good temporal agreement between the original MOD-NIR-PWV and GNSS-PWV at the GNSS stations. This suggests that the grid-based calibration model, which was based on the differences between ERA-PWV and MOD-NIR-PWV, could effectively improve the accuracy of MODIS water vapor products over China.

\section{Conclusions}

In this study, the accuracy of MODIS near-infrared PWV products collected from the Terra and Aqua platform during the six-year period from 2013 to 2018 over China was evaluated by comparing them against the two reference datasets: single-point PWV retrieved from 246 ground-based GNSS tracking stations and the two-dimensional PWV retrieved from ERA5 reanalysis datasets over China. To validate the suitability of using ERA-PWV as the reference for the grid-based calibration model developed for China, ERAPWV was compared with GNSS-PWV and RS-PWV. The statistical results showed good agreement: the means of biases and RMSs were 0.5 and $1.7 \mathrm{~mm}$ compared to GNSS-PWV, 0.4 and $1.9 \mathrm{~mm}$ compared to RS-PWV, and their correlation coefficients were above 0.959 and 0.894 , respectively.

After the validation, GNSS-PWV and ERA-PWV were used as the reference to evaluate the performance of MOD-NIR-PWV, since most of the large differences between the MODIS overpass time and radiosonde launch time were more than two hours. From the comparison of MOD-NIR-PWV to both GNSS-PWV and ERA-PWV in the six-year period studied, the non-normal distribution of the differences between the MOD-NIR-PWV and the two sets of reference data suggested that there exists a considerable systematic discrepancy in MODNIR-PWV over China. More specifically, the mean values of biases and RMSs were 2.9 and $3.8 \mathrm{~mm}$ compared to GNSS-PWV, and the values were 2.1 and $3.0 \mathrm{~mm}$ compared to ERAPWV, which implies the overestimation of MOD-NIR-PWV over China. In addition, the high correlation coefficient values between the MOD-NIR-PWV and both sets of reference data in most regions indicated the similar temporal trends of the three sets of PWV.

To mitigate systematic biases in the MODIS water vapor products over China, the differences between ERA-PWV and MOD-NIR-PWV from 2013 to 2018 at each grid point were used as the sample data to develop a $0.25^{\circ} \times 0.25$ grid-based calibration model of MOD-NIR-PWV based on a harmonic model with annual and semiannual periods. This was achieved through a periodic characteristic analysis of the sample data. To evaluate the performance of the developed calibration model, the calibrated MOD-NIR-PWV in the above-mentioned six-year period was compared to ERA-PWV and GNSS-PWV for the evaluation of precision and accuracy, respectively, of the model. The results show that the calibration model could not only significantly improve precision by $94 \%$ and accuracy by $53 \%$, but also weaken the non-normal distribution features of the differences between MOD-NIR-PWV and both sets of reference PWV. These results suggest that the developed grid-based calibration model can be used to improve the accuracy of MOD-NIR-PWV over China.

The main shortcoming of this study is that the test data (i.e., GNSS-PWV) used to evaluate the accuracy of the calibration model were from the same period as the sample data used to develop the model (2013-2018), due to the limited amount of available MODNIR-PWV in 2019 and 2020, which is desirable for a solid statistical result. Our future work will focus on using test data of multiple years later than those of the sample data (e.g., after 2018) to evaluate the performance of the grid-based calibration model.

Author Contributions: Conceptualization, D.Z. and K.Z.; methodology, D.Z.; software, D.Z.; validation, D.Z., L.Y. and S.W.; formal analysis, D.Z.; investigation, D.Z.; resources, D.Z.; data curation, D.Z. and L.Y.; writing—original draft preparation, D.Z.; writing—review and editing, D.Z., S.W. and L.L.; visualization, D.Z.; supervision, K.Z. and S.W.; project administration, K.Z.; funding acquisition, D.Z. and K.Z. All authors have read and agreed to the published version of the manuscript. 
Funding: This research was supported by the National Natural Science Foundations of China (No. 41730109), the China Postdoctoral Science Foundation (No. 2020M671645), the Natural Science Foundation of Jiangsu Province, China (No. BK20200646), the Postgraduate Research \& Practice Innovation Program of Jiangsu Province (KYCX21_2297).

Data Availability Statement: IGRA-2 radiosonde dataset can be obtained from ftp:/ ftp.ncdc.noaa. gov/pub/data/igra (accessed on 15 November 2020). ERA5 reanalysis data set can be freely available at https:/ / www.ecmwf.int/en/forecasts/datasets/reanalysis-datasets/era5 (accessed on 10 October 2020). MODIS water vapor products can be obtained from https:/ /ladsweb.modaps.eosdis.nasa.gov (accessed on 25 May 2021).

Acknowledgments: The author would like to thank NASA, CMONOC, IGRA, and ECMWF for providing MODIS PWV products,GNSS ZTD products, radiosonde observations and atmospheric data.

Conflicts of Interest: The authors declare no conflict of interest.

\section{References}

1. Gradinarsky, L.P.; Johansson, J.M.; Bouma, H.R.; Scherneck, H.-G.; Elgered, G. Climate monitoring using GPS. Phys. Chem. Earth, Parts $A / B / C$ 2002, 27, 335-340. [CrossRef]

2. Sherwood, S.C.; Roca, R.; Weckwerth, T.M.; Andronova, N.G. Tropospheric water vapor, convection, and climate. Rev. Geophys. 2010, 48, RG2001. [CrossRef]

3. Trenberth, K.E.; Fasullo, J.; Smith, L. Trends and variability in column-integrated atmospheric water vapor. Clim. Dyn. 2005, 24, 741-758. [CrossRef]

4. Zhai, P.; Eskridge, R.E. Atmospheric Water Vapor over China. J. Clim. 1997, 10, 2643-2652. [CrossRef]

5. Dai, A.; Wang, J.; Ware, R.H.; Van Hove, T. Diurnal variation in water vapor over North America and its implications for sampling errors in radiosonde humidity. J. Geophys. Res. Atmos. 2002, 107, ACL 11-1-ACL 11-14. [CrossRef]

6. Dessler, A.E.; Wong, S. Estimates of the water vapor climate feedback during el Niño-Southern Oscillation. J. Clim. 2009, 22, 6404-6412. [CrossRef]

7. Hodnebrog, Ø.; Myhre, G.; Samset, B.H.; Alterskjær, K.; Andrews, T.; Boucher, O.; Faluvegi, G.; Fläschner, D.; Forster, P.M.; Kasoar, M.; et al. Water vapour adjustments and responses differ between climate drivers. Atmos. Chem. Phys. 2019, 19, 12887-12899. [CrossRef]

8. Barreto, A.; Cuevas, E.; Damiri, B.; Romero, P.M.; Almansa, F. Column water vapor determination in night period with a lunar photometer prototype. Atmos. Meas. Tech. 2013, 6, 2159-2167. [CrossRef]

9. Ichoku, C. Analysis of the performance characteristics of the five-channel Microtops II Sun photometer for measuring aerosol optical thickness and precipitable water vapor. J. Geophys. Res. 2002, 107, 4179. [CrossRef]

10. Bevis, M.; Businger, S.; Herring, T.A.; Rocken, C.; Anthes, R.A.; Ware, R.H. GPS meteorology: Remote sensing of atmospheric water vapor using the global positioning system. J. Geophys. Res. 1992, 97, 15787. [CrossRef]

11. Brettle, M.J.; Galvin, J.F.P. Back to basics: Radiosondes: Part 1? The instrument. Weather 2003, 58, 336-341. [CrossRef]

12. Lindstrot, R.; Preusker, R.; Diedrich, H.; Doppler, L.; Bennartz, R.; Fischer, J. 1D-Var retrieval of daytime total columnar water vapour from MERIS measurements. Atmos. Meas. Tech. 2012, 5, 631-646. [CrossRef]

13. Liu, Z.; Wong, M.S.; Nichol, J.; Chan, P.W. A multi-sensor study of water vapour from radiosonde, MODIS and AERONET: A case study of Hong Kong. Int. J. Climatol. 2013, 33, 109-120. [CrossRef]

14. Khaikin, V.; Lebedev, M.; Shmagin, V.; Zinchenko, I.; Vdovin, V.; Bubnov, G.; Edelman, V.; Yakopov, G.; Shikhovtsev, A.; Marchiori, G.; et al. On the Eurasian SubMillimeter Telescopes Project (ESMT). In Proceedings of the 2020 7th All-Russian Microwave Conference (RMC), Moscow, Russia, 25-27 November 2020; IEEE: New York, NY, USA, 2020; pp. 47-51.

15. Gelaro, R.; McCarty, W.; Suárez, M.J.; Todling, R.; Molod, A.; Takacs, L.; Randles, C.A.; Darmenov, A.; Bosilovich, M.G.; Reichle, R.; et al. The Modern-Era Retrospective Analysis for Research and Applications, Version 2 (MERRA-2). J. Clim. 2017, 30, 5419-5454. [CrossRef]

16. Hersbach, H.; Bell, B.; Berrisford, P.; Hirahara, S.; Horányi, A.; Muñoz-Sabater, J.; Nicolas, J.; Peubey, C.; Radu, R.; Schepers, D.; et al. The ERA5 global reanalysis. Q. J. R. Meteorol. Soc. 2020, 146. [CrossRef]

17. Elliott, W.P.; Gaffen, D.J. On the Utility of Radiosonde Humidity Archives for Climate Studies. Bull. Am. Meteorol. Soc. 1991, 72, 1507-1520. [CrossRef]

18. Garand, L.; Grassotti, C.; Halle, J.; Klein, G.L. On differences in radiosonde humidity-reporting practices and their implications for numerical weather prediction and remote sensing. Bull. Am. Meteorol. Soc. 1992, 73, 1417-1423. [CrossRef]

19. Bokoye, A.I.; Royer, A.; O’Neill, N.T.; Cliche, P.; McArthur, L.J.B.; Teillet, P.M.; Fedosejevs, G.; Thériault, J.M. Multisensor analysis of integrated atmospheric water vapor over Canada and Alaska. J. Geophys. Res. Atmos. 2003, 108. [CrossRef]

20. Wolfe, D.E.; Gutman, S.I. Developing an Operational, Surface-Based, GPS, Water Vapor Observing System for NOAA: Network Design and Results. J. Atmos. Ocean. Technol. 1999, 17, 426-440. [CrossRef] 
21. Kishore, P.; Venkat Ratnam, M.; Namboothiri, S.P.; Velicogna, I.; Basha, G.; Jiang, J.H.; Igarashi, K.; Rao, S.V.B.; Sivakumar, V. Global $\left(50^{\circ} \mathrm{S}-50^{\circ} \mathrm{N}\right)$ distribution of water vapor observed by COSMIC GPS RO: Comparison with GPS radiosonde, NCEP, ERA-Interim, and JRA-25 reanalysis data sets. J. Atmos. Solar-Terrestrial Phys. 2011, 73, 1849-1860. [CrossRef]

22. Memmo, A.; Fionda, E.; Paolucci, T.; Cimini, D.; Ferretti, R.; Bonafoni, S.; Ciotti, P. Comparison of MM5 integrated water vapor with microwave radiometer, GPS, and radiosonde measurements. IEEE Trans. Geosci. Remote Sens. 2005, 43, 1050-1058. [CrossRef]

23. Trent, T.; Schröder, M.; Remedios, J. GEWEX Water Vapor Assessment: Validation of AIRS Tropospheric Humidity Profiles With Characterized Radiosonde Soundings. J. Geophys. Res. Atmos. 2019, 124, 886-906. [CrossRef]

24. Wang, J.; Dai, A.; Mears, C. Global Water Vapor Trend from 1988 to 2011 and Its Diurnal Asymmetry Based on GPS, Radiosonde, and Microwave Satellite Measurements. J. Clim. 2016, 29, 5205-5222. [CrossRef]

25. Ning, T.; Wickert, J.; Deng, Z.; Heise, S.; Dick, G.; Vey, S.; Schöne, T. Homogenized Time Series of the Atmospheric Water Vapor Content Obtained from the GNSS Reprocessed Data. J. Clim. 2016, 29, 2443-2456. [CrossRef]

26. Vey, S.; Dietrich, R.; Fritsche, M.; Rülke, A.; Steigenberger, P.; Rothacher, M. On the homogeneity and interpretation of precipitable water time series derived from global GPS observations. J. Geophys. Res. 2009, 114, D10101. [CrossRef]

27. Guerova, G.; Jones, J.; Douša, J.; Dick, G.; de Haan, S.; Pottiaux, E.; Bock, O.; Pacione, R.; Elgered, G.; Vedel, H.; et al. Review of the state of the art and future prospects of the ground-based GNSS meteorology in Europe. Atmos. Meas. Tech. 2016, 9, 5385-5406. [CrossRef]

28. Ning, T.; Elgered, G.; Willén, U.; Johansson, J.M. Evaluation of the atmospheric water vapor content in a regional climate model using ground-based GPS measurements. J. Geophys. Res. Atmos. 2013, 118, 329-339. [CrossRef]

29. Wang, J.; Zhang, L.; Dai, A.; Van Hove, T.; Van Baelen, J. A near-global, 2-hourly data set of atmospheric precipitable water from ground-based GPS measurements. J. Geophys. Res. 2007, 112, D11107. [CrossRef]

30. Manandhar, S.; Lee, Y.H.; Meng, Y.S.; Yuan, F.; Ong, J.T. GPS-Derived PWV for Rainfall Nowcasting in Tropical Region. IEEE Trans. Geosci. Remote Sens. 2018, 56, 4835-4844. [CrossRef]

31. Foster, J.; Bevis, M.; Schroeder, T.; Merrifield, M.; Businger, S.; Dorn, S.; Marcus, S.; Dickey, J.; Bar-Sever, Y. El Niño, water vapor, and the global positioning system. Geophys. Res. Lett. 2000, 27, 2697-2700. [CrossRef]

32. Wang, X.; Zhang, K.; Wu, S.; Li, Z.; Cheng, Y.; Li, L.; Yuan, H. The correlation between GNSS-derived precipitable water vapor and sea surface temperature and its responses to El Niño-Southern Oscillation. Remote Sens. Environ. 2018, 216. [CrossRef]

33. Zhao, Q.; Liu, Y.; Yao, W.; Ma, X.; Yao, Y. A Novel ENSO Monitoring Method using Precipitable Water Vapor and Temperature in Southeast China. Remote Sens. 2020, 12, 649. [CrossRef]

34. Zhao, Q.; Ma, X.; Yao, W.; Liu, Y.; Yao, Y. A Drought Monitoring Method Based on Precipitable Water Vapor and Precipitation. J. Clim. 2020, 33, 10727-10741. [CrossRef]

35. Gao, B.-C.; Yang, P.; Guo, G.; Park, S.K.; Wiscombe, W.J.; Chen, B. Measurements of water vapor and high clouds over the Tibetan plateau with the terra modis instrument. IEEE Trans. Geosci. Remote Sens. 2003, 41, 895-900. [CrossRef]

36. Hanssen, R.F. High-Resolution Water Vapor Mapping from Interferometric Radar Measurements. Science 1999, $283,1297-1299$. [CrossRef] [PubMed]

37. Lindenbergh, R.; Keshin, M.; van der Marel, H.; Hanssen, R. High resolution spatio-temporal water vapour mapping using GPS and MERIS observations. Int. J. Remote Sens. 2008, 29, 2393-2409. [CrossRef]

38. Shi, F.; Xin, J.; Yang, L.; Cong, Z.; Liu, R.; Ma, Y.; Wang, Y.; Lu, X.; Zhao, L. The first validation of the precipitable water vapor of multisensor satellites over the typical regions in China. Remote Sens. Environ. 2018, 206, 107-122. [CrossRef]

39. Wang, Y.; Yang, K.; Pan, Z.; Qin, J.; Chen, D.; Lin, C.; Chen, Y.; Lazhu; Tang, W.; Han, M.; et al. Evaluation of Precipitable Water Vapor from Four Satellite Products and Four Reanalysis Datasets against GPS Measurements on the Southern Tibetan Plateau. J. Clim. 2017, 30, 5699-5713. [CrossRef]

40. He, J.; Liu, Z. Water Vapor Retrieval From MODIS NIR Channels Using Ground-Based GPS Data. IEEE Trans. Geosci. Remote Sens. 2020, 58, 3726-3737. [CrossRef]

41. Bock, O.; Parracho, A.C. Consistency and representativeness of integrated water vapour from ground-based GPS observations and ERA-Interim reanalysis. Atmos. Chem. Phys. 2019, 19, 9453-9468. [CrossRef]

42. Parracho, A.C.; Bock, O.; Bastin, S. Global IWV trends and variability in atmospheric reanalyses and GPS observations. Atmos. Chem. Phys. 2018, 18, 16213-16237. [CrossRef]

43. Zhang, W.; Lou, Y.; Huang, J.; Zheng, F.; Cao, Y.; Liang, H.; Shi, C.; Liu, J. Multiscale Variations of Precipitable Water over China Based on 1999-2015 Ground-Based GPS Observations and Evaluations of Reanalysis Products. J. Clim. 2018, 31, 945-962. [CrossRef]

44. Zhao, Q.; Yao, Y.; Yao, W.; Zhang, S. GNSS-derived PWV and comparison with radiosonde and ECMWF ERA-Interim data over mainland China. J. Atmos. Solar-Terrestrial Phys. 2019, 182. [CrossRef]

45. Jiang, J.; Zhou, T.; Zhang, W. Evaluation of Satellite and Reanalysis Precipitable Water Vapor Data Sets Against Radiosonde Observations in Central Asia. Earth Sp. Sci. 2019, 6, 1129-1148. [CrossRef]

46. Zhang, W.; Zhang, H.; Liang, H.; Lou, Y.; Cai, Y.; Cao, Y.; Zhou, Y.; Liu, W. On the suitability of ERA5 in hourly GPS precipitable water vapor retrieval over China. J. Geod. 2019, 93, 1897-1909. [CrossRef]

47. Wang, S.; Xu, T.; Nie, W.; Jiang, C.; Yang, Y.; Fang, Z.; Li, M.; Zhang, Z. Evaluation of Precipitable Water Vapor from Five Reanalysis Products with Ground-Based GNSS Observations. Remote Sens. 2020, 12, 1817. [CrossRef] 
48. Chang, L.; Xiao, R.; Prasad, A.A.; Gao, G.; Feng, G.; Zhang, Y. Cloud mask-related differential linear adjustment model for MODIS infrared water vapor product. Remote Sens. Environ. 2019, 221, 650-664. [CrossRef]

49. Gui, K.; Che, H.; Chen, Q.; Zeng, Z.; Liu, H.; Wang, Y.; Zheng, Y.; Sun, T.; Liao, T.; Wang, H.; et al. Evaluation of radiosonde, MODIS-NIR-Clear, and AERONET precipitable water vapor using IGS ground-based GPS measurements over China. Atmos. Res. 2017, 197, 461-473. [CrossRef]

50. Liu, J. Precipitable water vapor on the Tibetan Plateau estimated by GPS, water vapor radiometer, radiosonde, and numerical weather prediction analysis and its impact on the radiation budget. J. Geophys. Res. 2005, 110, D17106. [CrossRef]

51. Liu, J.; Liang, H.; Sun, Z.; Zhou, X. Validation of the Moderate-Resolution Imaging Spectroradiometer precipitable water vapor product using measurements from GPS on the Tibetan Plateau. J. Geophys. Res. 2006, 111, D14103. [CrossRef]

52. Wang, R.; Liu, Y. Recent declines in global water vapor from MODIS products: Artifact or real trend? Remote Sens. Environ. 2020, 247, 111896. [CrossRef]

53. Bai, J.; Lou, Y.; Zhang, W.; Zhou, Y.; Zhang, Z.; Shi, C. Assessment and calibration of MODIS precipitable water vapor products based on GPS network over China. Atmos. Res. 2021, 254, 105504. [CrossRef]

54. Liu, H.; Tang, S.; Zhang, S.; Hu, J. Evaluation of MODIS water vapour products over China using radiosonde data. Int. J. Remote Sens. 2015, 36, 680-690. [CrossRef]

55. Liang, H.; Zhang, Y.; Cao, L.; Cao, Y. Temporal relations between precipitable water vapour and precipitation during wet seasons based on nearly two decades of data from the Lhasa River valley, Tibetan Plateau. Int. J. Climatol. 2020, 40, 1656-1668. [CrossRef]

56. Lu, N.; Qin, J.; Yang, K.; Gao, Y.; Xu, X.; Koike, T. On the use of GPS measurements for Moderate Resolution Imaging Spectrometer precipitable water vapor evaluation over southern Tibet. J. Geophys. Res. Atmos. 2011, 116, n/a-n/a. [CrossRef]

57. Li, X.; Long, D. An improvement in accuracy and spatiotemporal continuity of the MODIS precipitable water vapor product based on a data fusion approach. Remote Sens. Environ. 2020, 248, 111966. [CrossRef]

58. Li, Z. Comparison of precipitable water vapor derived from radiosonde, GPS, and Moderate-Resolution Imaging Spectroradiometer measurements. J. Geophys. Res. 2003, 108, 4651. [CrossRef]

59. Zhang, B.; Yao, Y.; Xin, L.; Xu, X. Precipitable water vapor fusion: An approach based on spherical cap harmonic analysis and Helmert variance component estimation. J. Geod. 2019, 93, 2605-2620. [CrossRef]

60. Sam Khaniani, A.; Nikraftar, Z.; Zakeri, S. Evaluation of MODIS Near-IR water vapor product over Iran using ground-based GPS measurements. Atmos. Res. 2020, 231, 104657. [CrossRef]

61. Liu, B.; Wang, Y.; Lou, Z.; Zhan, W. The MODIS PWV correction based on CMONOC in Chinese mainland. Acta Geod. Cartogr. Sin. 2019, 48, 1207. [CrossRef]

62. Davis, J.L.; Herring, T.A.; Shapiro, I.I.; Rogers, A.E.E.; Elgered, G. Geodesy by radio interferometry: Effects of atmospheric modeling errors on estimates of baseline length. Radio Sci. 1985, 20, 1593-1607. [CrossRef]

63. Dousa, J.; Elias, M. An improved model for calculating tropospheric wet delay. Geophys. Res. Lett. 2014, 41, 4389-4397. [CrossRef]

64. Zus, F.; Dick, G.; Douša, J.; Heise, S.; Wickert, J. The rapid and precise computation of GPS slant total delays and mapping factors utilizing a numerical weather model. Radio Sci. 2014, 49, 207-216. [CrossRef]

65. ICAO. ICAO Manual of the ICAO Standard Atmosphere Extended to 80 Kilometres (262,500 Feet); ICAO: Montreal, QC, Canada, 1993; Volume 7488, p. 305.

66. Saastamoinen, J. Atmospheric Correction for the Troposphere and Stratosphere in Radio Ranging Satellites. In The Use of Artificial Satellites for Geodesy; Wiley Online Library: Hoboken, NJ, USA, 2013; Volume 15, pp. 247-251.

67. Wang, J.; Zhang, L. Climate applications of a global, 2-hourly atmospheric precipitable water dataset derived from IGS tropospheric products. J. Geod. 2009, 83, 209-217. [CrossRef]

68. Leckner, B. The spectral distribution of solar radiation at the earth's surface-elements of a model. Sol. Energy 1978, 20, 143-150. [CrossRef]

69. Lomb, N.R. Least-squares frequency analysis of unequally spaced data. Astrophys. Space Sci. 1976, 39, 447-462. [CrossRef] 